Bond University

Research Repository

\title{
Improving efficiency in roading projects: a New Zealand study
}

Haji Karimian, Saeed; Mbachu, Jasper; Egbelakin, Temitope; Shahzad, Wajiha

Published in:

Engineering, Construction and Architectural Management

DOI:

10.1108/ECAM-02-2018-0060

Licence:

Other

Link to output in Bond University research repository.

Recommended citation(APA):

Haji Karimian, S., Mbachu, J., Egbelakin, T., \& Shahzad, W. (2019). Improving efficiency in roading projects: a New Zealand study. Engineering, Construction and Architectural Management, 26(5), 827-849.

https://doi.org/10.1108/ECAM-02-2018-0060

\section{General rights}

Copyright and moral rights for the publications made accessible in the public portal are retained by the authors and/or other copyright owners and it is a condition of accessing publications that users recognise and abide by the legal requirements associated with these rights.

For more information, or if you believe that this document breaches copyright, please contact the Bond University research repository coordinator. 


\section{IMPROVING EFFICIENCY IN ROADING PROJECTS: A NEW ZEALAND STUDY}

\section{ABSTRACT}

Road Pavement Maintenance and Rehabilitation Contractors (RPMRCs) - and indeed all contractors handling public sector projects - face challenges inherent in performance-based rewards which seek to maximize tax dollar by ensuring whole-of-life best value in the project delivery process. To be successful, contractor's productivity and performance should remain high and resilient to internal and external constraints in the project environment. There is little research on the priority constraints to productivity and performance in the New Zealand (NZ) roading sector. This study aimed to contribute by filling the gap in existing knowledge by investigating the key productivity constraints faced by New Zealand RMRCs and the associated mitigation measures. This paper presents preliminary findings of an interview-based exploratory survey of senior managers and directors of medium- to large-sized road contracting firms in New Zealand. Empirical data were analysed using the multi-attribute analytical technique.

Results revealed 70 productivity constraints faced by the RPMRCs in New Zealand; In diminishing order of influence, these were aggregated into eight broad categories as follows: finance, workforce, technology/ process, statutory/regulatory compliance, project characteristics, project management/project team characteristics, unforeseen circumstances, and other/ external factors. The report highlights the most important constraints in the eight broad categories.

The findings contribute to knowledge by revealing critical factors constraining productivity performance of NZ RMRCs and the associated improvement measures. New and more enriching viewpoints were provided on how contractors could leverage their limited resources to address the identified key constraints.

Keywords: Pavement, performance, productivity, road, roading, maintenance, rehabilitation.

\section{INTRODUCTION}

It is acknowledged that a well-constructed, well operated and routinely maintained road network is the critical enabler of economic growth (NZTA, 2014a). This is because a well-maintained road network enhances and sustains national and regional communications in a more effective, efficient and safe manner, which in turn, helps support a thriving New Zealand (NZTA, 2014b).

McPherson and Olsen (2016) is a recent study documented that the New Zealand Transport Agency's (NZTA's) investment in the operation and maintenance of state highway network in the country is around $\$ 500$ million per annum, with per annum rehabilitation/ upgrading costs amounting to $\$ 1.5$ billion (NZTA, 2014b). According to Transit New Zealand (Transit NZ, 2000), more than 56 percent of its annual budget is allocated to general maintenance, reseal and pavement rehabilitation works in order to facilitate an adequate level of service to road users and to counter rapid pavement deterioration rate.

Currently, the New Zealand road network assets are valued at \$26 billion (approx.), and one of the most significant challenges faced by decision makers in the New Zealand roading industry is on how to ensure that every single dollar invested in road infrastructure development, operation and maintenance maximizes its value to the taxpayers. Consequently, the expectations from service providers are increased and they are expected to do a lot of work with little incentive. This situation is frustrating for the road contractors responsible for design, construction, and maintenance of road infrastructure networks as they are put under enormous pressure to optimise their work in order to maximize value delivery in the process.

However, productivity and performance of road maintenance contractors have been hindered due to facing enormous constraints where they are at the forefront of road infrastructure asset development and delivery, it, therefore, can result in reducing the extent of value they can deliver. The productivity constraints have brought about major setbacks to infrastructure project delivery such as cost overruns, delays, failed procurement or unavailability of finance (Pell et al., 2015). Therefore, having clear knowledge of existing constraints that contractors face in their day to day project implementation as well as knowing the mitigation measures can help roading contractors improve their productivity and performance. 
There are several studies that have looked at the challenges faced by the contractors in the infrastructure asset delivery and maintenance projects. For instance, the UK's Network Rail (2014) posed issues such as capacity limitations, poor performance management and progress tracking, poor safety management, unproductive organizational culture, weather and climate as some of the constraints faced by service providers in infrastructure asset development and maintenance. Other issues included poor asset strategic planning, lack of policies and communication, as well as supply chain limitations (Assaf and Al-Hejji, 2006). Moreover, a study conducted by McKinsey (2013) concluded that taking higher risks that are not commensurate with their reward in the contract is a major problem for contractors at the tendering and contract signing stage and this often results in serious resource constraints during the implementation phase. The Controller and Auditor General's Office (2011) identified New Zealand specific challenges in public infrastructure asset development and management these include issues such as acute skill shortage, unrealistic public expectations, the fiscally constrained environment within which infrastructure asset is procured and managed, and the type of procurement and contracting strategies adopted for infrastructure development which are not necessarily the most appropriate for bringing about collaborative working relationships and successful project delivery and achievement of set objectives.

Though a number of studies have investigated constraints faced by roading contractors, there is a lack of prioritization of these challenges - especially in the context of the New Zealand roading maintenance sector. While understanding the identified challenges that roading contractors are facing in overseas countries can be beneficial to New Zealand roading maintenance contractors, knowing the specific constraints and challenges faced by New Zealand contractors in their day-to-day operation is very crucial for contractors to improve their productivity and performance, as challenges identified in overseas countries may not be wholly applicable in New Zealand context. Over and above that, investigating what mitigation measures are applicable to the specific New Zealand roading sector context can help to maximise the productivity rate. While overseas studies are robust in regard to addressing some of these questions, there is a lack of empirical studies in the New Zealand context. This study will aim to contribute to bridging the existing information gap. Empirical data will comprise structured interview-based feedback provided by experienced roading contractors who were involved in road pavement design, construction, maintenance and rehabilitation projects in New Zealand.

\section{RESEARCH AIM AND OBJECTIVES}

This research is aimed at investigating the challenges that are hindering the productivity and performance of road pavement maintenance and rehabilitation contractors in New Zealand and also provides practical and innovative ways of tackling the existing constraints and challenges.

The specific objectives of the study are as follows.

1) To identify and prioritise the factors constraining contractors' productivity and performance in the road pavement maintenance and rehabilitation process (RPMR).

2) To explore measures for mitigating the identified constraints with a focus on improving efficiency and productivity in the RPMR project delivery.

\section{LITERATURE REVIEW}

\section{Productivity in context}

Depending on the context and the objectives, 'Productivity' can be a complex concept that is interpreted in a variety of ways. From a production system perspective, Bjork (2003) defines productivity as the ability of a system to convert input resources into outputs. This efficiency perspective of productivity expresses the concept as a quantitative relationship between the output and the input. It does not address the effectiveness criterion. Unfortunately, this efficiency perspective is widely adopted by economists. For instance, Schreyer (2001), while relaying the economists' perspective of the concept defined it as the ratio of a measure of output to a measure of resource input.

The economist's or efficiency perspective of productivity is not entirely helpful to the construction industry stakeholders in terms of offering a quantitative tool for measuring and benchmarking project performance. 
The Statistics New Zealand (2016) corroborated the inadequacies of the efficiency-only perspective of the concept and its lack of effectiveness focus by noting that "the economist's perspective of the concept (i.e., the output to input ratio measure) is not a measure of effectiveness because it reflects only how much extra output is produced per unit of input, not whether that input has a productive outcome. To provide a more relevant definition that is consistent with the project performance measurement and benchmarking needs of the industry, a number of authors have come up with some definitions. For instance, Chan and Chan (2004) defined the concept as a measure of the extent of achievement of project goals or objectives, namely time, cost, quality and scope accomplishments.

Performance measurement is a widely accepted definition of productivity, especially among construction industry stakeholders. Performance measurement expresses productivity in the context as a measure of how well resources are leveraged to achieve set targets or desired outputs (Durdyev and Mbachu, 2011). This definition of productivity is adopted in this study as it is consistent with the research objectives.

\section{Productivity and Performance in the Context of Road Pavement Maintenance and Rehabilitation - NZTA's Perspective}

As the client or employer to roading contractors in New Zealand, the NZTA specifies criteria based on seven indicators, for assessing contractors' performance of the work category they are prequalified to undertake. Contractors are required to meet or exceed the classification level input requirements for all the above seven performance criteria as a condition to maintain their classification level for the work category they have been prequalified to carry out the project on.

The performance criteria as set out in the Contractor Prequalification Application (NZTA, 2016) is as follows:

1. Quality assurance

2. Traffic management

3. Environmental management

4. Health and safety

5. Project management

6. Quantum or size of work

7. Co-operative and pro-active partnering.

Therefore, from the perspective of the NZTA, contractor's productivity and performance are assessed based on the extent to which the contractor is able to perform in relation to the above-listed factors. As some of the criteria do not have objective measures of accomplishment and therefore require subjective assessment, it is uncertain how NZTA conducts the assessment. However, in its document that sets forth the bases for contractor payment in the Network Outcomes Contract (NZTA, 2015), it is evident that productivity and performance is primarily based on accomplishment of the schedule, cost and quality targets, but with compliance with the seven criteria being constraints that must be managed well - at least to the threshold level.

\section{Implication for current research}

As indicated in earlier sections, the strategic or effectiveness perspective on productivity was adopted in this study as it is more consistent with the research objectives; it is also the perspective that resonates well with the industry stakeholders' use of the concept as a tool for measuring performance towards the four key project objectives - cost, schedule, scope and quality targets. Feedback received from the study participants is expected to be underpinned by this perspective of the concept, whereby their reflections on the productivity constraints and mitigation measures were expected to draw upon their understanding of the factors that could influence the achievement of the set project targets.

\section{Constraints in road pavement maintenance and rehabilitation projects}

Identifying key constraints in improving productivity and performance in RPMR is essential to be able to direct available resources towards eliminating, mitigating, or transferring the risks involved (Diewert, 2001; Dunston et al., 2000). A few studies have been conducted in the past to identify productivity constraints in road pavement maintenance projects. However, within the construction sector, Durdyev and Mbachu (2011) 
provided a holistic model of internal and external productivity constraints that is based on a global framework, 'PESTELI' (Political, Economical, Socio-Cultural, Technology, Legal/Political, and Industrial constraints). Also, internal constraints can be modeled from the scope of the ' $6 \mathrm{Ms}$ ' of the business process improvement (McKinsey, 2013) as: money/finance, management of the workforce, manpower, machinery, materials, and method process. Also, a study by Chan et al. (2001) with a focus on RPMR, listed numerous factors related to improving productivity and performance in road pavement maintenance. The authors showed that proper management of the identified potential delay factors could improve productivity rates. However, none of these studies provided a prioritized list of measures for mitigating the constraints.

\section{Summary of review of literature and gap in knowledge}

Review of literature to date has provided insights into the key concepts that underpin this research and the extent to which the research objectives have been addressed in previous studies. It was found that while several studies have been completed in the research area, such as Lee et al. (2002) and Mbachu and Seadon (2013), few studies exist in the New Zealand context. The New Zealand roading sector and especially roading maintenance sector is unique in many respects, such as socio-cultural dynamics, regulations, industry characteristics, and legislation. Overseas findings relating to the topic may, therefore, not be wholly applicable in the New Zealand context given its unique settings. In addition, the productivity constraints identified in other countries were largely unprioritised.

Presenting New Zealand contractors with recommendations on a number of productivity constraints and improvement measures without some form of prioritisation will not be particularly helpful; it will only amount to 'information overload'. This study will address this knowledge gap by investigating productivity constraints and improvement measures that are unique to the New Zealand roading sector. In addition, the constraints will be prioritised in order of their relative influence levels, so the contractors can focus on their limited resources by addressing those constraint factors and improvement measures, who have the highest impact on productivity outcomes.

\section{RESEARCH METHOD}

A two-stage descriptive survey method involving pilot and structured interviews was adopted for this phase of the study; this is consistent with the exploratory nature of the research goal (Ellis \& Kumar, 2015).

Scope of data sources was limited to views expressed by senior managers and directors of contracting firms involved in road pavement design, construction, maintenance and rehabilitation in New Zealand as provided in the 30 April 2016 edition of the NZTA Register of Prequalified Contractors (NZTA, 2016). The NZTA register provided the sampling frame for the study.

\section{Pilot interviews}

The first stage of empirical data gathering involved the use of in-depth pilot interviews conducted with experienced contractors in the roading industry. A selective and purposive sampling method (Bernard, 2017) was used to select convenience samples of senior managers and directors of contracting firms that make up the sampling frame. Participation was on the basis of willingness to grant approximately one hour for an indepth interview. Six contractors agreed to be interviewed. These were recruited from each of three main regions of New Zealand - Auckland, Christchurch, and Wellington. The aim of the interviews was to explore the key factors that are constraining productivity performance in road pavement maintenance and rehabilitation projects in New Zealand. Also, questions were asked about the key improvement measures which the interviewees believed could enhance success in the delivery of road pavement maintenance and rehabilitation projects.

\section{Structured interviews}

An open-ended questionnaire was developed using the constructs identified at the pilot interviews. Before being used for the structured interviews, the questionnaire was pre-tested for clarity and relevance. Subsequently, invitations were extended to 60 senior managers and directors of contracting firms in the 
sampling frame who was based in Auckland, Wellington, and Christchurch; the invitees did not participate in the pilot interviews and the questionnaire pre-tests. The intention was to recruit about 60 contractors who could grant quality time for the structured interview, comprising 20 from each of the three main regions. The open-ended sections of the structured questionnaire served to elicit from the interviewees further constructs that were not included in the list identified during the pilot interviews.

\section{Data analysis}

The data collected for this study during structured interviews was analyses using the multi-attribute analytic method. The use of this technique was deemed appropriate because the aim of study was to prioritise the relative levels of influence or effectiveness of the individual items in subsets based on the mean ratings assigned to them by the research participants (Chang and Ive (2002). The analysis involved computing the mean rating (MR) value, as the average of participants' collective ratings of a variable on the rating scale used. MR was calculated as the sum of the product of each rating point $(\mathrm{P})$ assigned to the $i^{\text {th }}$ item in the subset, and the corresponding proportion of participants is assigning the rating point to the item (i.e. $\mathrm{R}_{\%}$ ). Mbachu (2011) provided a modified form of Chang and Ive (2002) expression for computing the mean rating as shown in Equation 1.

$\mathrm{MR}=\sum_{i=1}^{5}\left(P_{i} \times R_{i} \%\right)$

Where: $\mathrm{P}_{\mathrm{i}}=$ Rating point $i\left(1 \leq i \leq 5\right.$ - for 5 -point Likert scale); $\mathrm{R}_{\mathrm{i}} \%=$ Percentage response to rating point, $I$, out of the total number of respondents in the survey.

\section{RESULTS AND DISCUSSIONS}

\section{Survey Responses}

A total of 60 prospective interviewees were invited to participate in the structured interviews designed for this study. 58 out of 60 prospective interviewees agreed to take part and out of those 58,56 participants provided usable responses. Responses from two out of five interviewees who chose to complete the online version of the questionnaire rather than participating in the face-to-face or phone interviews were grossly incomplete.

The survey responses confirmed that the constructs generated during the pilot interviews were robust and provided a comprehensive list of the productivity constraining factors and their mitigation measures. Some additional factors were supplied by the study participants in the open-ended sections of the completed questionnaire, but they were mostly the parapharased versions of constraints already listed.

\section{Demographic Profile}

\section{NZTA 's prequalification categories of the interviewees' firms}

Analysis of demographic profile of the interview participants showed that out of the NZTA's four prequalification categories for contractors, the majority (i.e., 70\%) worked for contracting firms that belonged to the road surfacing work category. Others worked for contracting firms in the categories of general road construction (20\%) and bridge construction (10\%). None of the study participant worked for contracting firms in the routine and minor works category. The findings at this stage of the research were therefore biased towards the opinions of senior managers and directors of contracting firms that specialized in road surfacing jobs. The higher proportion of interviewees in this category was a positive outcome, given their direct relevance to the focus of the research. 


\section{Length of experience of the participants}

A vast majority (i.e., $82 \%$ ) of the interview participants had at least 10 years of experience in the roading industry in New Zealand, as key members of the project teams. Feedback from this group therefore enhanced the quality of the study findings.

\section{Status of the participants in their organisations}

Majority of the participants (i.e., 74.5\%) were senior managers/project managers \& contract managers. The smallest proportion of participants (i.e., 25.5\%) was from project engineers, site engineers, design engineers and team leaders.

\section{Findings; First Research Objective}

The first objective of this study was to identify and prioritise the factors that could constrain contractors' productivity performance in the road pavement maintenance and rehabilitation process (RPMR).

\section{Broad- and sub-categories of factors constraining contractors' productivity performance}

Findings from the first phase pilot interviews revealed 70 constraint factors which were aggregated into eight themes: finance, workforce, technology/ process, statutory/regulatory compliance, project characteristics, project management/project team characteristics, unforeseen circumstances, and other/ external factors. The broad categories and the sub-constraint factors are summarised in Table 1. The table also provides the subconstraints under each broad category. The sub-constraints under each broad category are listed in diminishing order of influence as constraint factors.

\section{$<$ Table 1 here $>$}

\section{Discussions}

The following subsections present discussions on the findings in relation to the eight broad categories of constraints highlighted in Table 1.

\section{Project finance related constraints}

Table 1 shows that out of the nine sub-constraint factors identified under the broad category of project finances, the three most influential constraints to roading contractors' productivity and performance are the problem of inadequate supply or high cost of needed resources: money, men, materials, $\&$ machinery which is consistence with the finding of Durdyev et al. (2011). The second influential factor is lack of collaboration between consultant \& contractor. A study by Ozorhon, Abbott, Aouad, \& Powell (2010) has also concluded that the use of good coordination skills can enhance collaboration among key stakeholders such as client, contractor, consultants, suppliers that can help to ensure maximum value delivery from design through production and construction to operation of a road maintenance project.

The inaccurate estimate is the third most influential factors under the category of project finance related constraints. This finding is consistent with Peshkin et al. (2007) conclusion that contractors themselves cause their problems by not accurately estimating the full costs of work prior to coming up with a tender figure. Perhaps, this problem is prevalent because of the competitive tendering process that is often based on lowest conforming tender which is mostly used for public sector contracts (Lee et al., 2002). In order to avoid being uncompetitive, contractors may intentionally underestimate so they can win jobs but with the ulterior motive of making up their profit expectations from variation claims.

\section{Workforce-related constraints}

Ten sub-constraints were analysed under the workforce-related broad category. The most influential is the contractor's lack of good leadership/management capability. Müller and Turner (2010) argued that poor project management capability has huge impact on project outcomes largely due to poor coordination of the various stakeholder's inputs in the project delivery process. 


\section{Technology/process related constraints}

Under this broad category, ineffective approach to road maintenance in road maintenance projects featured as the most influential constraints out of the eight constraints in the group. This is consistent with the finding of Giustozzi, Crispino, and Flintsch (2012). They have presented that keeping road pavements at high service levels is achievable only through an effective preventive maintenance approach during the pavement service life that has been proven to provide significant improvement of the road pavement performance and reduce deterioration rate of the road pavement.

Also, inadequate training on new processes and technologies and resistance to accepting new technologies and technique and methods for road maintenance $\&$ rehabilitation projects are the second and third important factors under the category of Technology/Process constraints. Peshkin et al. (2007) found that resistance to technology-driven change is usually due to the time and resources involved in training on the use new technologies or simply because contractors are not convinced that the benefits are worth the investment. This is largely on account of a short-term view of the benefits of technology.

\section{Project characteristics related constraints}

Table 1 shows that the broad category of project characteristics comprised eight constraints. The two most influential in the group relates to unfavorable time frames within which most roadworks must be carried out and site location and associated environmental constraints such as traffic congestion, climate, subsoil, and topography. This finding is consistent with Lee et al. (2002) statement that location/time-frame based construction logistics issues such as road restrictions and traffic volume can significantly influence productivity and performance in road maintenance projects. In addition, Phillips and Kazmierowski (2010) concluded that sub-soil conditions could and indeed have a high level of impact on the productivity of road projects.

\section{Project management/ project team characteristics}

Out of the 12 constraints identified under the broad category of project management/project team characteristics, issues relating to the frequency of design changes or late change orders exert the highest influence. This finding agrees with the conclusions of Alinaitwe et al. (2007) that late change orders especially at critical stages of the project implementation - could slow down progress; and if the principal to the contract refuses to accept the changes as true variation under the contract conditions, the contractor bears the full risks which could constrain the cash flow and completion time.

\section{Statutory/ regulatory compliance}

Under this broad category, issues related to compliance with the Health and Safety At Work Act 2015 featured the most influential out of the nine sub-constraints in the group. Seven factors rated and analysed under the broad category of statutory compliance. This should be expected because of the huge fines associated with a violation under the new Act. For instance, Work Safe New Zealand (WorkSafe NZ, 2016) advised that Category 1 offence under the new Act attracts the highest penalty for a company (up to $\$ 3$ million), for the individual as an officer ( $\$ 600,00$ or five-year years in jail or both) and individual as a worker $(\$ 300,000$ or five-year years in prison or both).

\section{Unforeseen circumstances}

Only four constraints were identified under this broad category; the inclement weather was rated as the highest influential factor among the four constraints. In the context of construction, Makulsawatudom et al. (2004) define 'inclement weather' as harsh or severe atmospheric conditions that are beyond the level that could be forecast or predicted even by weather experts and which are not conducive for workers to carry on their work unprotected without being exposed to danger. Similarly, the New Zealand Standard 3910 include inclement weather as part of conditions for variation entitlements only if a reasonable contractor is not able to foresee the weather pattern during the weather period of work; however, the variation entitlements are not an option under lump sum fixed price contracts with no allowance for contract adjustment. The high risk associated with this constraint is due to its prevalence in the road pavement maintenance and rehabilitation projects, especially considering the performance-based contracts that are used for the projects, which place most risks on the contractors. 
Other external factors

Eleven factors were identified under this group, with the highest influencing factor being issues relating to market conditions and level of competition in the industry. This finding should be expected given that the New Zealand construction industry, in general, is prone to boom-bust cycle which has been identified as one of the most significant problems hindering productivity and growth of the industry (Academy of Constructing Excellence New Zealand, CAENZ, 2015). The issues stemmed from cash flow problems associated with under-pricing during periods of stiff competition or resource problems associated with taking on too many jobs beyond company's resource capacity during the boom phase.

\section{Relative levels of impact of the broad categories of constraint factors on contractors' productivity and performance}

Table 2 presents the result of multi-attribute analysis of the participants' ratings on the relative levels of impact of the broad categories of constraint factors on RPMR contractors' productivity and performance. The table shows that out of the eight broad constraint factors, the workforce-related constraint category was rated as having 'High' impact with 3.60 rating value and Project management/ project team characteristics factors was rated as a second influential factor with having 'High' impact, out of following six categories which are project characteristics, project finance, technology/process, unforeseen events, and statutory compliance and other external factors such as economic, political, industry, \&, etc.

In many respect, this result is not consistent with related findings in previous studies. For instance, Lee et al. (2002) and Peshkin et al. (2007) concluded that cash flow or project finance - being the lifeblood of the business - has the potential to exert the most profound influence on productivity and performance of contractors handling public and private sector projects. Also statutory/ regulatory compliance issues should have received very high rating given the increasingly over-regulated environment within which contractors operate in New Zealand, especially in relation to the new Health and Safety At Work Act 2015 which stipulates extremely high fines - up to $\$ 1$ million and/ or five year jail term - for non-compliance (WorkSafe NZ, 2016).

Also, the World Economic Forum (2016) noted that digitalization, innovative technologies, and new construction techniques have vast potential for improving productivity and efficiency in the industry and hence transformation to a more resilient and prosperous future. Inadequate or out-dated technology and the process has the opposite effect.

Perhaps, the perception that workforce-related issues encapsulate all the other problems could contribute to this result. For instance, statutory penalties occur when workers fail to do what they are supposed to do in terms of adhering to the specified compliance standards in work. Cash flow or financial issues arise when workers fail to be prudent in their work processes and involve in excessive wastage, shoddy work or idleness.

$<$ Table 2 here $>$

\section{Findings; Second Research Objective}

The second objective of the study was to explore measures for mitigating the identified constraints, with a view to improving efficiency and productivity in the road pavement maintenance and rehabilitation (RPMR) project delivery process. Table 3 presents the findings in relation to mitigation measures for addressing the identified constraints with a view to improving productivity and performance.

$<$ Table 3 here $>$ 


\section{Open Ended Feedback}

$<$ Figure 1 here $>$

In the open-ended sections of the questionnaire, the interviewees provided further suggestions for mitigating constraints and improving productivity and performance of the contractors in the road pavement maintenance and rehabilitation projects. The unedited recommendations are as follows.

1- "Currently jobs have to be milled, filled, and finished in one day. This means for every site you need a traffic management team, milling, and paving crew. If you could have independent milling and paving crews, you could double the output. Each crew could mill or pave for 8-10 hours per shift, instead of 4-6 hours each. The number of crews could be reduced, and cost per ton laid would be significantly reduced".

2- "Allow for greater disturbance to the public in order to have projects completed more efficiently and cheaper. Timing and availability of road closures is important - if we had full closures we could complete whole lot more work".

3- "Across the board realisation that financial difficulties on smaller to medium contractors (i.e., not the big four main contractors in NZ) are reducing actual competition in the industry (which helps the big four). Genuine competition needs to occur and packages that suit contractors other than the big four need to be considered. Large companies are underbidding maintenance contracts to remove local competition".

4- "Use of more effective and efficient materials: e.g., use more SBS modified binders in place of current materials; and emulsion-based products in place of current products".

5- "Use of partnering in the project procurement to achieve win-win outcomes for all."

6- "Any changes in the programme of projects and the associated delivery timeframe goals that have been agreed by all parties (contractors, client, stakeholders and etc.) should not happen without clear and quantifiable 
7- "Teams need to share motivation for achieving project goals. Where there are competing drivers, then it's hard to work towards a common goal. An agile approach to programming means there is a little certainty to contract teams about workload. This means that it is difficult to commit resources and even harder to engage sub-contractors to the programmes that are subject to changes. This is a supply chain issue and prevents a team from gaining any momentum in continuous improvement."

8- "Understanding how the asset is likely to perform over time and determine the correct treatment at the first signs intervention. Understanding the impacts of heavy vehicles traveling on the various classes of roads and observe changes to the environment and pavement surface."

9- "In all aspects of the project, from procurement to construction - Plan the Work / Work the Plan. Engage with the 'Constructor' as early as possible in the process and be collaborative in the delivery."

10- "The local industry is well regarded internationally as being highly advanced, getting excellent outcomes for the dollars spent. It needs to be remembered that this is a small country with limited budgets, maintaining a lot of roads in difficult geological and climatic conditions. The industry has sufficient suppliers and competitive tensions that drive innovation and stretch performance."

11- "Undertake an honest analysis of true costs of the large outcome based road maintenance contracts (include NZTA and council costs) vs. what is achieved in terms of actual tangible outputs such as physical maintenance completed. These contracts simply have a lot of staff managing processes rather than actually being productive constructing the project. They promote doing as little as possible to meet KPIs and make a profit that clearly won't improve productivity."

\section{CONCLUSIONS AND RECOMMENDATION}

This study aimed to investigate the priority constraints road pavement maintenance, and rehabilitation (RPMR) contractors face in New Zealand (NZ) as well as strategies for improvement. Preliminary findings of an interview-based qualitative survey of medium- to large-sized roading contractors in NZ revealed 70 productivity constraints which were aggregated into eight broad categories as follows: finance, workforce, technology/ process, statutory/regulatory compliance, project characteristics, project management/project team characteristics, unforeseen circumstances, and other/ external factors.

The result of multi-attribute analysis of the relative levels of influence of the broad constraint categories on RPMR contractors' productivity and performance shows that only the workforce-related constraint category was rated as being 'High' on a 5-point influence rating scale. In diminishing order of influence, the following six constraint categories were rated as being 'Moderate': Project management/ project team characteristics, project characteristics, project finance, technology/process, unforeseen events, and statutory compliance. Other external factors were perceived as being of low influence, indicating that the bulk of the constraints faced by the contractors stemmed from sources internal to the project environment.

Nineteen sets of measures were identified for mitigating the productivity constraints with a view to improving the contractors' productivity and performance. The most effective measure related to proper planning at the outset. The 19 sets of constraint mitigation measures were clustered under five broad categories, comprising technology/ process, human resources management, leadership/ project management, contract and financial management and external measures. Leadership/ project management was found as the most effective set of mitigation measures since this cluster comprises the majority of mitigation measures that received 'High' to 'Very high' ratings.

The findings have advanced existing knowledge by revealing critical factors constraining productivity performance of RPMR contractors in New Zealand, as well as effective measures for improvement.

The key limitation of the findings at this stage of the research is that it is based on feedback from a limited number of participants which were not representative of the potential participants in the sampling frame for the study. As a result, the findings cannot be reliably generalised beyond the scope of the data used. Further research on the subject is recommended to ensure that representation of the views of the individuals and companies that comprised the sampling frame is achieved. The current findings will provide the starting point for the future research as potential propositions or hypotheses to be tested. 


\section{REFERENCES}

Allan, N., Yin, Y. and Scheepbouwer, E. (2008). "A study into the cyclical performance of the New Zealand construction industry", available at: http://theacademy.co.nz/a-study-into-the-cyclical-performance-of-the-newzealand-construction-industry-part-1/ ( accessed 20 July 2016)

Alinaitwe, H.M., Mwakali, J.A. and Hansson, B. (2007). "Factors affecting the productivity of building craftsmen $\square$ studies of Uganda". Journal of Civil Engineering and Management, 13(3), pp.169-176.

Assaf, S.A. and Al-Hejji, S. (2006). "Causes of delay in large construction projects". International journal of project management, 24(4), pp.349-357.

Bernard, H.R. (2017). Research methods in anthropology: Qualitative and quantitative approaches. Rowman \& Littlefield.

Björk, B.C. (2003). "Electronic Document Management in Construction-Research Issue and Results".

Chan, A.P. and Chan, A.P. (2004). "Key performance indicators for measuring construction success". Benchmarking: an international journal, 11(2), pp.203-221.

Chan, W.T., Fwa, T.F. and Hoque, K.Z. (2001). "Constraint handling methods in pavement maintenance programming". Transportation Research Part C: Emerging Technologies, 9(3), pp.175-190.

Chang, C.Y. and Ive, G. (2002). "Rethinking the multi-attribute utility approach based procurement route selection technique". Construction Management \& Economics, 20(3), pp.275-284.

Controller and Auditor-General's Office, 2011. Challenges facing the public sector and our responses, Annual Plan 2011/12, Part, available at: http://www.oag.govt.nz/2011/2011-12/part3.htm (accessed 10 May 2016)

Diewert, W. E. (2001). "The measurement of productivity", Bulletin of Economic Research, 44(3), 163-198.

Dunston, P.S., Savage, B.M. and Mannering, F.L. (2000). "Weekend closure for construction of asphalt overlay on urban highway". Journal of construction engineering and management, 126(4), pp.313-319.

Durdyev, S. and Mbachu, J. (2011). "On-site labour productivity of New Zealand construction industry: Key constraints and improvement measures". Construction Economics and Building, 11(3), pp.18-33.

Ellis Jr, R.D., and Kumar, A. (2005). "Influence of nighttime operations on construction cost and productivity". Transportation Research Record, (1389).

Giustozzi, F., Crispino, M. and Flintsch, G. (2012). "Multi-attribute life cycle assessment of preventive maintenance treatments on road pavements for achieving environmental sustainability". The International Journal of Life Cycle Assessment, 17(4), pp.409-419.

Ozorhon, B., Abbott, C., Aouad, G. and Powell, J. (2010). "Innovation in construction: A project life cycle approach". Salford Centre for Research and Innovation in the Built Environment (SCRI) Research Report, 4.

KPMG, (2013), "Project delivery strategy: Getting it right, Leadership Series 7, Project Advisory", available at: https://www.kpmg.com/NZ/en/IssuesAndInsights/ArticlesPublications/project-leadership/Documents/KPMGPALS-7-project-delivery-strategy.pdf (accessed 10 June 2016)

Lee, E.B., Harvey, J., William Ibbs, C. and St. Martin, J. (2002). "Construction productivity analysis for asphalt concrete pavement rehabilitation in urban corridors". Transportation Research Record: Journal of the Transportation Research Board, (1813), pp.285-294.

Mbachu, J. (2011). "Sources of contractor's payment risks and cash flow problems in the New Zealand construction industry: Project team's perceptions of the risks and mitigation measures". Construction management and economics, 29(10), pp.1027-1041.

Mbachu, J. and Seadon, J. (2013). Productivity Improvement in Building Life Cycle. Development Process, RolePlayers and Efficiency Improvement, Bookboon.com

McKinsey. (2013). "Risk-Management Approach to a Successful Infrastructure Project", Working Papers, McKinsey \& Company, available at:

http://www.mckinsey.com/ /media/McKinsey/dotcom/client_service/Risk/Working\%20papers/52_A_riskmanagement approach to a successful infrastructure project.ashx (accessed 10 July 2016)

McPherson, J. and Olsen, C. (2016). "Selecting the best model for your road maintenance contract", research paper presented at the Institute of Public Works Engineering Australasian (IPWEA) conference, 22-25 June, Auckland, New Zealand, avilable at: http://www.ipwea.org/HigherLogic/System/DownloadDocumentFile.ashx?DocumentFileKey=fe0b25ff-98130f27-815d-91c9151c0e54\&forceDialog $=0$ (accessed 10 July 2016)

Müller, R. and Turner, R. (2010). Leadership competency profiles of successful project managers. International Journal of Project Management, 28(5), pp.437-448.

Network Rail (2014). "Asset Management Policy (March), London, UK", available at: http://www.networkrail.co.uk/publications/asset-management-policy-March-2014.pdf (accessed 10 April 2016)

New Zealand Transport Agency (NZTA). (2016). "Prequalified Contractors As Of 30 April 2016", availble at: https://www.nzta.govt.nz/assets/resources/prequalified-contractors/prequalified-contractors.pdf (accessed 10 July 2016) 
New Zealand Transport Agency (NZTA). (2014a). "Research on the economic impact of transport users in New Zealand urban shopping centers makes an important local contribution to the growing international interest in the reallocation of road space", available at: http://www.nzta.govt.nz/resources/research/reports/530 (accessed 10 April 2016)

New Zealand Transport Agency (NZTA). (2014b). State Highway Activity Management Plan 2015-18 (Isbn 978-0-478-41971-9, available at: http://www.nzta.govt.nz/assets/network/management/docs/draft-shamp2015-18.pdf

Pell, R; Svoboda, R; Eagar, R; Ondko, P. and Kirschick, F. (2015). "Effective Infrastructure Asset Management, Prism, 1(2), pp. 30-75, available at: http://www.adlittle.com/downloads/tx adlprism/Asset Management 01.pdf (accessed 10 July 2016 )

Peshkin, D.G., Pierce, P.L.M. and Krstulovich Jr, J.M. (2009). "Consideration of pavement preservation in mechanistic-empirical design and analysis of pavement structures", National Cooperative Highway Research Program, Transportation Research Board, NCHRP project, pp.20-07.

Phillips, T., \& Kazmierowski, T. (2010). "Improving pavement friction and aggregate skid resistance on Ontario Highways", available at: http://www.mto.gov.on.ca/english/transtek/roadtalk/rt16-3/

Statistics New Zealand (Stats NZ) (2016). "Frequently asked questions about productivity - General", available at: http://www.stats.govt.nz/browse_for_stats/economic_indicators/productivity/prod-faqs/prodfaqs-general.aspx (accessed 20 July 2016 from)

Schreyer, P. (2001). The OECD productivity manual: a guide to the measurement of industry-level and aggregate productivity. International Productivity Monitor, 2(2), pp.37-51.

Transit New Zealand. (2000). "State Highway Asset Management Manual, Wellington, Transit New Zealand", available at: https://www.nzta.govt.nz/assets/resources/state-highway-asset-managementmanual/docs/SM020-manual.pdf (accessed 10 June 2016)

World Economic Forum. (2016). "Shaping the future of construction: A breakthrough in mindset and technology, Industry Agenda", available at: http://www3.weforum.org/docs/WEF_Shaping the Future of Construction full report .pdf (accessed 20 July 2016 from)

Work Safe NZ. (2016). "Offences and penalties under the Health and Safety At Work Act 2015, Fact Sheet", available at: http://www.business.govt.nz/worksafe/information-guidance/all-guidance-items/hswa-factsheets/offences-and-penalties-under-the-health-and-safety-at-work-act-2015/offences-and-penalties-underhswa.pdf. (accessed 20 July 2016) 
Appendix: Figure 1: Measures for mitigating constraints and improving productivity and performance in the road pavement maintenance and rehabilitation projects

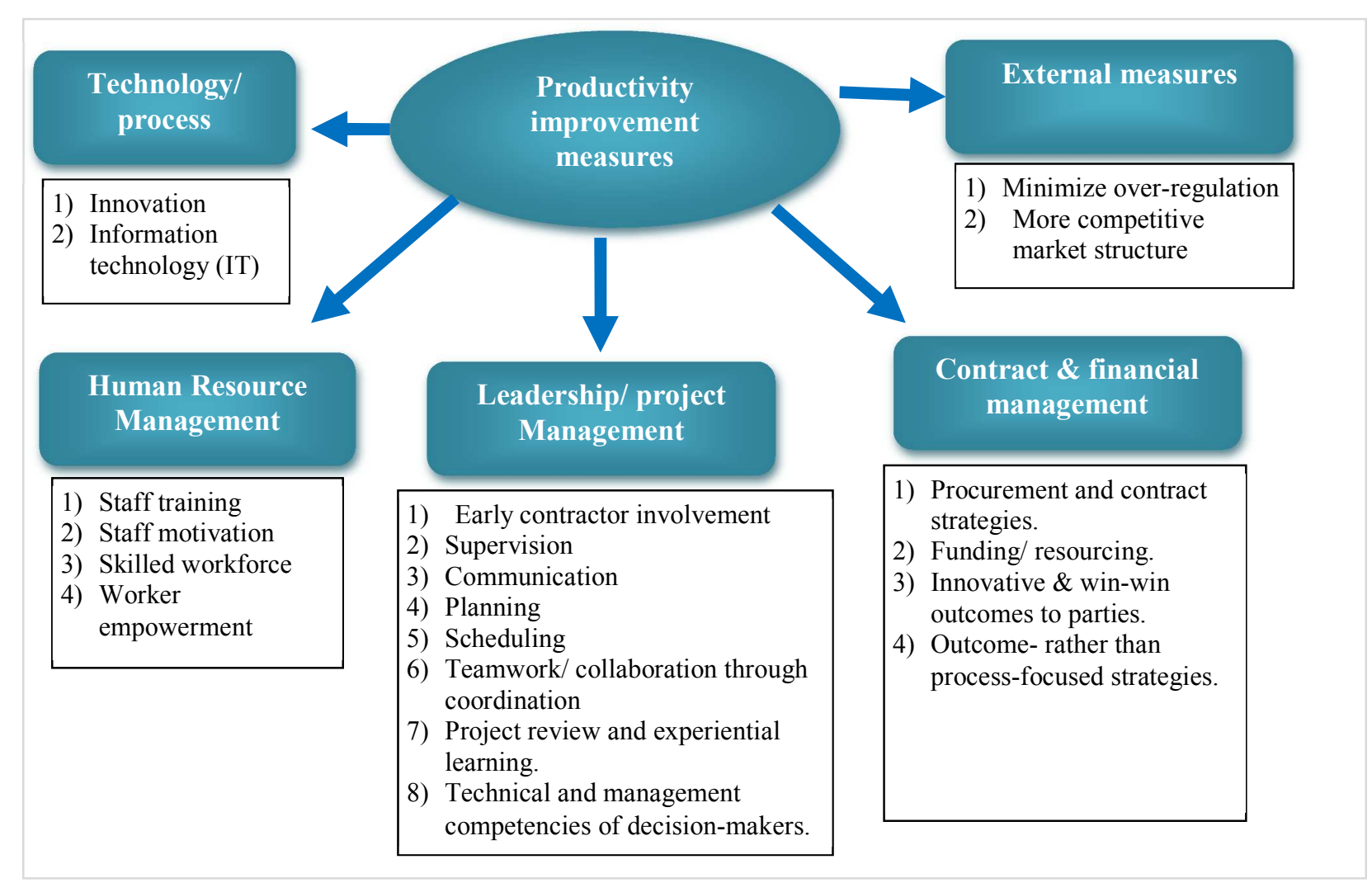


Appendix: Table 1-Broad and sub-categories of factors constraining contractors' productivity performance in road pavement maintenance and rehabilitation projects in New Zealand

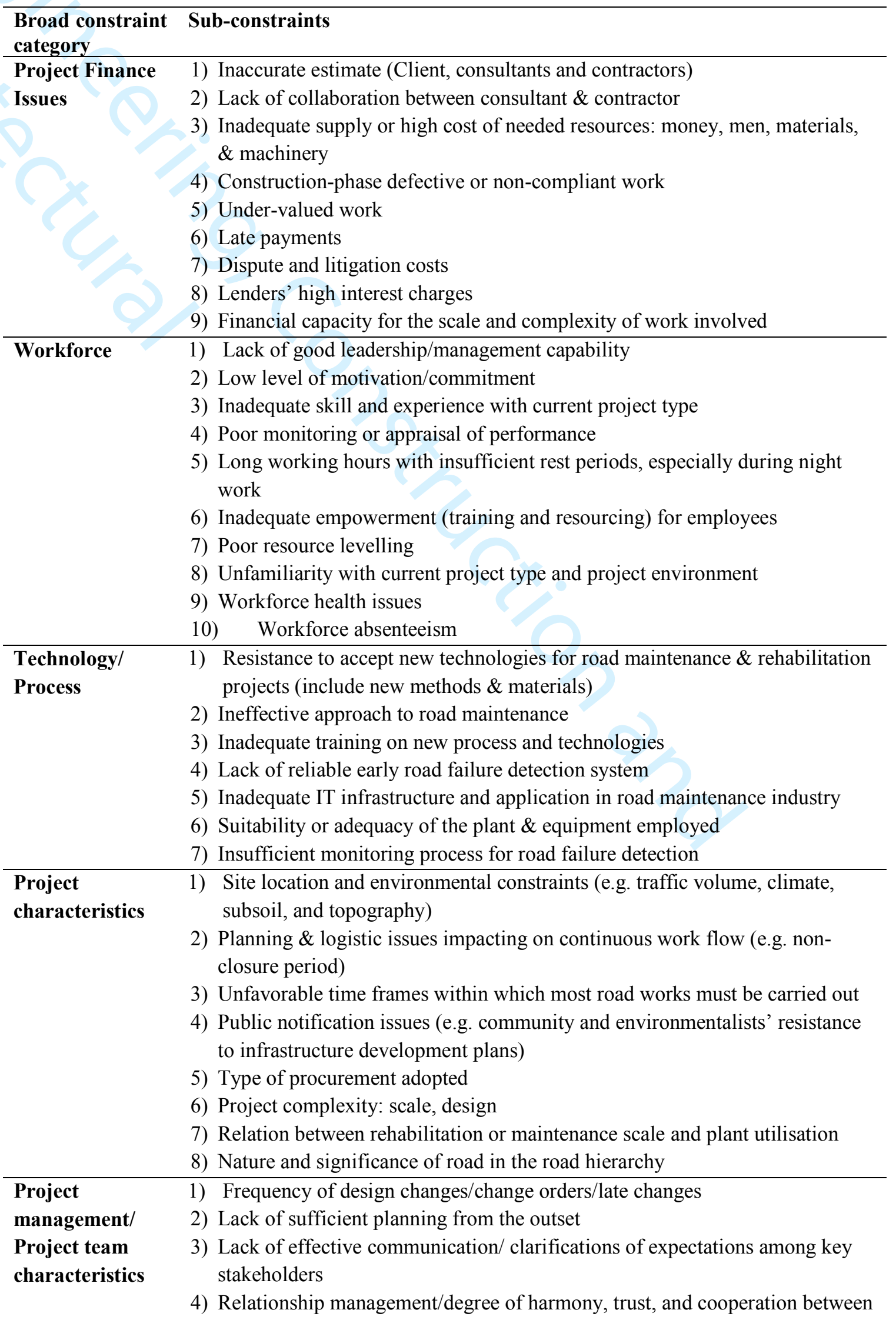


contractor, consultant, and council

5) Lack of organisational learning: Learning from previous projects

6) Client's overt influence on the project process

7) Lack of proper and regular coordination, supervision, performance monitoring, and control

8) Experience and competencies of the project team

9) Lack of project organisational culture that supports high productivity and performance

10) Poor project management and risk management process

11) Poor supply chain management, especially as it relates to "just-in-time" supply principles

12) Supplier related issues (delays, inferior goods)

\begin{tabular}{ll}
\hline Statutory/ & 1) Health \& Safety at Work Act \\
Regulatory & 2) Resource Management Act \\
compliance & 3) Local Authority Bylaws \\
& 4) Construction Contracts Act \\
& 5) Employment Relationship Act \\
6) Consumer Guarantees Act \\
7) Fair trading Act \\
8) Statutory Consent Compliance \\
circumstances & 1) Inclement weather \\
\hline 2) Unforeseeable ground conditions forcing design revisions \\
factors & 3) On-site accidents \\
4) Natural disasters/Acts of God \\
\hline 1) Market conditions and level of competition in the industry for jobs \\
2) Inflation/ fluctuations in material prices \\
3) Energy crises/ rising costs \\
4) Frequent changes in government policies/ legislation impacting on \\
5) Interest rate/ cost of capital \\
6) Fluctuations in exchange rate \\
7) Post-construction defective or non-compliant work \\
8) User/Client value perceptions \\
9) Durability of completed work within the defects liability period or warranty/ \\
guarantee \\
10) Post completion deterioration rate relating to rough use \\
11) In-use conditions being at variance with prior production assumption
\end{tabular}




\section{Appendix: Table 2- Relative levels of impact of the broad categories of constraint factors on contractors' productivity and performance}

\begin{tabular}{|c|c|c|c|c|c|c|c|c|}
\hline \multirow{2}{*}{$\begin{array}{l}\text { Broad categories } \\
\text { of constraint } \\
\text { factors }\end{array}$} & \multicolumn{5}{|c|}{ Ratings on relative levels of impact } & \multirow{2}{*}{$\begin{array}{l}\text { Mean } \\
\text { rating } \\
\text { (Eq.5) }\end{array}$} & \multirow{2}{*}{$\begin{array}{l}\text { Level } \\
\text { of } \\
\text { Impact }\end{array}$} & \multirow[t]{2}{*}{$\begin{array}{c}\text { Respo } \\
\text { nses }\end{array}$} \\
\hline & $\begin{array}{l}\text { Very } \\
\text { Low }\end{array}$ & Low & $\begin{array}{c}\text { Moderat } \\
\mathrm{e}\end{array}$ & High & $\begin{array}{l}\text { Very } \\
\text { High }\end{array}$ & & & \\
\hline 1. Project finance & $6 \%(3)$ & $\begin{array}{l}34 \% \\
(17)\end{array}$ & $\begin{array}{l}32 \% \\
(16)\end{array}$ & $\begin{array}{l}22 \% \\
(11)\end{array}$ & $6 \%(3)$ & 2.88 & $\begin{array}{l}\text { Moder } \\
\text { ate }\end{array}$ & 50 \\
\hline 2. Workforce & $2 \%(1)$ & $4 \%(2)$ & $\begin{array}{l}40 \% \\
(20)\end{array}$ & $\begin{array}{l}40 \% \\
(20)\end{array}$ & $14 \%(7)$ & 3.60 & High & 50 \\
\hline $\begin{array}{l}3 . \\
\text { Technology/Proce } \\
\text { ss }\end{array}$ & $2 \%(1)$ & $\begin{array}{l}36 \% \\
(18)\end{array}$ & $\begin{array}{l}48 \% \\
(24)\end{array}$ & $10 \%(5)$ & $4 \%(2)$ & 2.78 & Low & 50 \\
\hline $\begin{array}{l}\text { 4. Project } \\
\text { characteristics }\end{array}$ & $2 \%(1)$ & $\begin{array}{l}24 \% \\
(12)\end{array}$ & $\begin{array}{l}46 \% \\
(23)\end{array}$ & $\begin{array}{l}22 \% \\
(11)\end{array}$ & $6 \%(3)$ & 3.06 & $\begin{array}{l}\text { Moder } \\
\text { ate }\end{array}$ & 50 \\
\hline $\begin{array}{l}\text { 5. Project } \\
\text { management/ } \\
\text { project } \\
\text { team } \\
\text { characteristics }\end{array}$ & $\begin{array}{l}2.04 \% \\
(1)\end{array}$ & $\begin{array}{l}16.33 \\
\%(8)\end{array}$ & $\begin{array}{c}32.65 \% \\
(16)\end{array}$ & $\begin{array}{c}32.65 \% \\
(16)\end{array}$ & $\begin{array}{c}16.33 \% \\
(8)\end{array}$ & 3.45 & $\begin{array}{l}\text { Moder } \\
\text { ate }\end{array}$ & 49 \\
\hline $\begin{array}{l}\text { 6. Statutory } \\
\text { regulatory/compli } \\
\text { ance }\end{array}$ & $\begin{array}{l}10 \% \\
(5)\end{array}$ & $\begin{array}{l}40 \% \\
(20)\end{array}$ & $\begin{array}{l}38 \% \\
(19)\end{array}$ & $8 \%(4)$ & $4 \%(2)$ & 2.56 & Low & 50 \\
\hline $\begin{array}{l}\text { 7. Unforeseen } \\
\text { circumstances }\end{array}$ & $6 \%(3)$ & $\begin{array}{l}22 \% \\
(11)\end{array}$ & $\begin{array}{l}36 \% \\
(18)\end{array}$ & $\begin{array}{l}26 \% \\
(13)\end{array}$ & $10 \%(5)$ & 3.12 & $\begin{array}{l}\text { Moder } \\
\text { ate }\end{array}$ & 50 \\
\hline $\begin{array}{l}\text { 8. Other external } \\
\text { forces (economic, } \\
\text { political, industry, } \\
\text { etc) }\end{array}$ & $\begin{array}{l}14 \% \\
(7)\end{array}$ & $\begin{array}{l}48 \% \\
(24)\end{array}$ & $\begin{array}{l}30 \% \\
(15)\end{array}$ & $6 \%(3)$ & $2 \%(1)$ & 2.34 & Low & 50 \\
\hline
\end{tabular}




\section{Appendix: Table 3- Measures for improving productivity in the road maintenance and rehabilitation projects}

12roan rating of

Constraint mitigating/ productivity Improvement measures

Early contractor involvement: Encourage early contractor involvement in the design and planning and planning phase to ensure buildability and more innovation that can reduce costly and time-consuming variation and rework associated with design solutions not aligning with practical site conditions.

Supervision: Proper supervision of the workforce to minimise idle time, poor productivity and work progress

Communication: Ensure effective communication network to permit adequate information flow for clarity and prompt decision-making, especially between consultants and contractors. This can lead to proper investigation before contracting phase.

Respon effective Remar

se ness

$48 \quad 4.27$

Very

Planning: Proper planning should be done upfront to establish the benchmarks for downstream performance reviews and progress update; also provide plans for other challenges such as risks for statutory compliance (health and safety, environmental impact, traffic management, etc.)

Skilled workforce: Ensuring only qualified and experienced workers are employed to mitigate poor quality of workmanship and accidents on sites

Staff training: Provide adequate training programme to update and broaden staff skills on current best practices and trends, e.g., new occupational health and safety requirements on site. Up-skill the people are making the decisions - i.e., engineers, clients, and contractors.

Teamwork/ collaboration through coordination: Use good coordination skills to foster collaboration among key stakeholders - client, contractor, consultants, suppliers, etc. - to work collaboratively and ensure maximum value delivery from design through production and construction to operation and maintenance.

Worker empowerment through engagement: Involve all those that will implement the project in the planning and decision-making process so everyone knows the goals and expectations and can take ownership and commit to overall outcome achievement, as well get updated on changes.

Project review and experiential learning: Revisiting completed projects and learning from mistakes or better ways of achieving things outside the square

Innovation and win-win outcomes: Minimise red-tape and bureaucracy in decision-making processes; encourage innovation and share equally any associated rewards for cost and time savings among contributors.

Scheduling: Proper scheduling of operations to smoothen peaks and troughs in resource demand in line with resource ceilings/ capacity. Schedule work to minimise impact of weather; e.g., weather affected

$4.10 \quad$ Very
High

3.98 High

3.88 High

3.88 High

$49 \quad 3.80 \quad$ High


works should not be planned in winter

Staff motivation: Provide adequate incentives to motivate staff for peak performance

Outcome-rather than process-focused: Focus on outcomes rather than a process to avoid the current practice of missing the goal and 'covering of tracks just in case things might go wrong.'

Technical and management competencies of decision-makers: Improve technical/practical knowledge and management capability of road authority engineers \& consultants to align their decisions to practical realities and in line with contractors' innovative processes for optimum productivity and outcomes

erate

Procurement and contract strategies: Clients should rethink preference for lowest price conforming tenders and traditional system approaches to more collaborative procurement and contract strategies that focus on life cycle value and win-win outcomes for all stakeholders.

Funding/resourcing: Provide adequate funding and cash flow to ensure good progress and quality of work; ensure adequate level of resources to suit work demands and optimise efficiency and utilisation (i.e., not too much or too little plant and people resource)

Information technology (IT): Integration of IT in the work processes to improve efficiencies, productivity, and performance, using minimal resource inputs.

Minimising over-regulation: Minimise regulatory and statutory controls that inhibit innovation and creativity towards efficiencies and productivity. The regulators should be in partnership with the service providers, get on-board and work as teams, guiding each other along the way rather than waiting for mistakes and passing on blames.

More competitive market structure: Resolve oligopoly to improve efficiencies through fostering competition and innovation. Encourage smaller work packages to enable small to medium competitors to compete for jobs rather than having gigantic projects that only a few big companies have the capacity to compete for, which excludes the majority of the SMEs. 